$\begin{array}{rll}\text { Artvin Çoruh Üniversitesi } & \text { Artvin Coruh University } \\ \text { Orman Fakültesi Dergisi } & \text { Journal of Forestry Faculty } \\ \text { ISSN:2146-1880, e-ISSN: 2146-698X } & \text { ISSN:2146-1880, e-ISSN: 2146-698X } \\ \text { YII: 2015, Cilt: 16, SayI:1, Sayfa: 94-100 } & \text { Year: 2015, Vol: 16, Issue: 1, Pages: } 94-100\end{array}$

http://edergi.artvin.edu.tr

Araştırma makalesi

\title{
Doğu kayınında (Fagus orientalis Lipsky) yükseltiye bağlı olarak transpirasyon, yaprak buhar basınç açıklığı ve yaprak su potansiyeli değişimi
}

\section{Effects of altitude on transpiration, leaf vapor pressure deficit and leaf water potential in oriental beech}

Fatih BAYRAKTAR, Fahrettin TILKI

Artvin Çoruh üniversitesi, Orman Fakültesi, Orman Mühendisliği Bölümü

Özet

Bu çalışmada, Doğu kayınında transpirasyon $(E)$, yaprak buhar basınç açıklığı $\left(V_{\text {pdl }}\right)$ ve yaprak su potansiyeli $\left(\Psi_{\mathrm{L}}\right)$ fizyolojik parametrelerinin yükseltiye bağlı olarak değişimlerinin araştırıması amaçlanmıştır. Artvin-Ortaköy'de doğal olarak yayılış gösteren doğu kayınının bulunduğu meşcerede aynı bakı ve aynı toprak yapısı belirlenerek ölçümlerin farkının sadece yükseltiden kaynaklanabilecek değişiklikler olmasına özen gösterilerek fizyolojik değişiklikler belirlenmeye çalışılmıştır. Çalışma sonucunda, yükseltiye bağı olarak transpirasyon ve yaprak buhar basınç açıklığının arttığı, buna karşın yaprak su potansiyeli değerinin ise önemli oranda azaldığı belirlenmiştir.

Anahtar kelimeler: Doğu kayını, transpirasyon, yaprak buhar basınç açıklığı, yaprak su potansiyeli

Abstract

This study was designed to determine the effect of altitude on transpiration, leaf vapor pressure deficit and leaf water potential in oriental beech (Fagus orientalis Lipsky). The study area was located in Ortaköy, Artvin, and the experimental area had the same soil structure and aspect. The study showed that transpiration and leaf vapor pressure deficit increased but leaf water potential decreased by altitudinal gradient.

Key words: Fagus orientalis, transpiration, leaf vapor pressure deficit, leaf water potential

\section{GíRiş}

Ağaçlar genel olarak yerel koşullara, geliştirdikleri ekofizyolojik karakteristiklerle iyi uyum sağlamaktadır (Chabot ve Hicks 1982; Kikuzawa 1989; Bresson ve ark. 2009). Yükselti değişiklikleri düşük sıcaklık gibi, jeofiziksel etkilerin flora ve faunanın ekolojik ve evrensel olarak belirlenmesinde en kuvvetli "doğal deneyim" metodudur (Körner 2007). Gelişen teknolojiyle aynı türlerin farklı yerlerdeki gelişim ve büyümelerinin incelenmesi geçmişe oranla günümüzde daha da kolaylaşmaktadır. Yükseltinin değişmesiyle birlikte etkilenen sıcaklık, ışık, $\mathrm{CO}_{2}$ kısmi basıncı ve diğer çevresel değişkenlerin fotosentezi etkilenmesinden dolayı, rakım, gelişimi etkileyen önemli bir etken olarak düşünülmektedir (Tranquillini 1964; Hiesey ve ark. 1971; Körner ve Diemer 1987; Friend ve Woodward 1990; Kumar ve ark. 2005). Yükseltinin bitki fizyolojisi ve ekolojisinin üzerine etkileri düşünülürken sadece ışık emisyonundaki yapraklardaki ve diğer uygun şartlardaki gaz değişimleri değil, çevresel tüm faktörler dikkate alınmalıdır (Gale 1972a,b). Işık yoğunluğu, toprak nemi, besin maddeleri gibi çevresel faktörler, ağaçlardaki içsel olayları değiştirerek ağaçların kantitatif ve kalitatif olarak gelişmelerini etkilemektedirler (Kramer ve Kozlowski 1960). Bu değişimlerden yaprak buhar basınç açıklığı, bitki yaprak su potansiyeli, stomaların durumlarına göre transpirasyon gibi özellikler de etkilenmektedir. Sıcaklık, yağış ve rüzgâr gibi etmenlerin yükseltiye bağı olarak değişimi bitkilerdeki fizyolojik özelliklerin de değişmesine neden olmaktadır. Stomada olan en önemli çevresel değişkenlerden biri yaprak ve atmosfer arasındaki buhar basınç açıklığıdır (Addington ve ark. 2004). 
Buhar halindeki su moleküllerinin konsantrasyonu, aynı zamanda bulunduğu yerin çeperine ve sıvı yüzeyine yaptığı basınç ile gösterilebilir. Bu basınç, buhar basıncı olarak adlandırılır. Buhar konsantrasyonu buhar basıncıyla orantılı olduğundan, gaz halindeki su moleküllerinin hareketi yüksek buhar basınçlı bölümden düşük buhar basınçlı bölüme doğru olur (Kadıoğlu 2011). Topraktaki nemden dolayı strese maruz kalan bitkiler iyi sulanan bitkilere göre artan buhar basınç eksikliğine genellikle düşük bağıl stomatal hassasiyet gösterirler (Ludlow 1980; Cunningham 2004). Yapraktaki buhar basınç açıklığının iyi sulanan sera bitkilerinde $0.45 \mathrm{kPa}$ ila $1.25 \mathrm{kPa}$ arasında olması idealdir. Bu oranın artması bitkinin topraktan daha çok su çekme eğilimini artırır (Prenger ve Ling 2001; Morales ve ark. 2008). Çok sayıda araştırmacı tarafından stomatal tepkiler ve birçok model yayınlanmasına rağmen stomaların, buhar basınç açıklığına (VPD) verdiği fizyolojik kontrol mekanizma tepkileri tamamen anlaşılamamıştır (Li ve Li 2014). Anderson (1936) yaptığı çalışmada aynı atmosferik koşulların farklı sıcaklıklarda sağlanabilmesi için farklı bağıl nemlere intiyaç duyulduğunu ve bu değerler arasındaki ilişkiyi belirleme de buhar basınç açıklığını ölçmenin daha avantajlı olduğunu ifade etmektedir.

Transpirasyon bitkinin ısısını düzenleyen bir olaydır. Bitkiler, topraktan aldıkları suyun \%90'dan fazla miktarını transpirasyon yoluyla atmosfere verirler ve bu olay sayesinde yapraktaki ISI enerjisinin birikimi dağıtılmış olur. Transpirasyonla kaybedilen suyun \%90'dan fazlası yapraklarla gerçekleştirilir. Transpirasyonla kaybedilen suyun çok az bir kısmı ise genç sürgün ve yan dalların korteksindeki küçük açıklıklarla sağlanır. Yapraklardan meydana gelen transpirasyonun $\% 90-95$ 'i stomalardan yapılır. Belli zamanda ölçülen ve belli ilkeye göre ifade edilen transpirasyon, transpirasyon hızı olarak tanımlanır. Transpirasyon hızı saat, gün, mevsim gibi zaman aşamaları ilkesine göre belirlenir. Bitkilerde transpirasyon hızını etkileyen en önemli faktör stoma açıklı̆ı̆ır. Bunun dışında transpirasyonu etkileyen bazı bitkisel ve ortamsal faktörler de (kök/gövde oranı, yaprak alanı, yaprak yapısı, havanın nemi, ışık, sıcaklık, rüzgar, karbondioksit konsantrasyonu, toprak suyu gibi) söz konusudur (Kacar ve ark. 2009; Hetherington ve Woodward 2003; Kadıoğlu 2011). Transpirasyon ölçümünü gerçekleştirmek için çeşitli yöntemler kullanılmıştır (tartı yöntemi, bitki organlarından yararlanılarak, potometre yöntemi, küvet yöntemi, renk değiştirme yöntemi vb.). Bitkiler, fotosentez ve transpirasyondan ödün vermemek için yerel ve küresel çevre değişikliklere uyum sağlamada gelişmiş strateji ve mekanizmalar geliştirmişlerdir (Kacar ve ark. 2009; Hetherington ve Woodward 2003; Li ve Li 2014).

Bitki fizyologlarının su potansiyeli olarak tanımladıkları bitki içindeki kimyasal potansiyel, suyla enerjinin sayısal bir ifadesidir ve paskal su potansiyelinin yaygın ölçüm birimidir. Su potansiyeli, topraktan bitkiye ve bitki içerisindeki su hareketleri ile bitkinin genel su durumu hakkında bilgi vermektedir. Su potansiyelinin $\left(\Psi_{\mathrm{w}}\right)$ başlıca üç bileşeni; çözelti içinde çözünen maddelerin potansiyeli ya da osmotik potansiyel $\left(\Psi_{s}\right)$, basınç potansiyeli $\left(\Psi_{\mathrm{p}}\right)$ ve yerçekimi potansiyeli $\left(\Psi_{\mathrm{g}}\right)^{\prime}$ dir. Osmotik potansiyel, molekül ya da iyonlar şeklinde suda çözünmüş madde miktarına bağlı olarak değişir. Osmotik potansiyel değerleri bitkinin tipine ve büyüme ortamına bağlı olarak değiş̧ebilir. Turgor potansiyeli ise hücrede bağımsız şekilde bulunan su moleküllerinin membran yüzeylerine ve hücre duvarlarına çarpmaları sonucu oluşur. İyi sulanmış bitkilerin yapraklarında, su potansiyeli -0,2 ile -0,1 MPa arasında değişirken kserofit bitkilerde bu oran çok daha düşük olabilmektedir. Bitki su potansiyeli ölçümlerinde farklı yöntemler kullanılabilmektedir (psikrometrik yöntem, basınç odası yöntemi, krioskopik geçiş ölçme yöntemi gibi) (Taiz ve Zeiger, 2008; Kacar ve ark. 2009).

Bu çalışmada, Artvin'de doğal olarak yayılış gösteren Doğu kayını (Fagus orientalis Lipsky)'nın bulunmuş olduğu meşcerelerde aynı bakı ve aynı toprak yapısında, ölçümlerin farkının sadece yükseltiden kaynaklanabilecek değişiklikler olması düşünülen 
Artvin-Ortaköy bölgesinde yükseltiye bağlı olarak, transpirasyon, yaprak buhar basınç açıklığı ve bitki yaprak su potansiyeli fizyolojik parametrelerinin değişimlerinin araştırılması amaçlanmıştır.

\section{MATERYAL ve YÖNTEM}

Çalışma alanı olarak Artvin Ortaköy Pırnallı Köyü istenilen özelliklere uygun alan olarak seçilmiştir. Çalışmada birinci seçilen alanın yükseltisi $1484 \mathrm{~m}$ ve ikinci alanın yükseltisi $1162 \mathrm{~m}$ olarak belirlenmiştir (Tablo 1). Seçilen alanlar yağış etkenliği sınıfına göre nemli orman karakteri taşımaktadır (Tablo 2). Çalışma alanında her iki yükseltide ortak parametreleri sabit olarak taşıyan meşcerelerden 5'er ağaç seçilmiştir. İki farklı yükselti gradiyentinde çalışılan deneme alanlarının doğu kayınının doğal olarak yayılış gösterdiği meşcerelerde aynı bakı, aynı toprak yapısı belirlenerek ölçümler elde edilmiştir. Transpirasyon ve yaprak buhar basınç eksikliklerinin ölçümü için LI-COR 6400 XT Portable Photosynthesis system cihazı kullanılmıştır. Su potansiyel değerleri psikrometrik yöntemle Wescor Psypro cihazı kullanılarak ölçülmüştür. Çalışmada kullanılan psikrometrik yöntem, suyun buhar basıncına dayalıdır; yüzeyden buharlaşan su o yüzeyi soğutur ilkesine dayanmaktadır (Taiz ve Zeiger 2008).

Tablo 1. Çalışma alanlarının durumu

\begin{tabular}{lcc}
\hline & 1. Çalışma Sahası & 2. Çalışma Sahası \\
\hline Enlem & 4202926 & 4203738 \\
Boylam & 4116308 & 4115979 \\
Eğim (\%) & $60-70$ & $65-70$ \\
Bakı & Kuzeybatı & Kuzeybatı \\
Yükselti (m) & 1484 & 1162 \\
\hline
\end{tabular}

Her iki yükseltide; seçilen her ağaçta aynı yerde olmasına dikkat edilerek seçilen 3'er yaprağın (diğer yapraklar tarafından örtülmeyen, tam güneş gören, azami genişlemesini yapmış olan, yaralı olmayan, böcek istilasına uğramamış ve gözle görülür stresten kaynaklı renk bozukluğu yahut kıvrılma olmayan) net

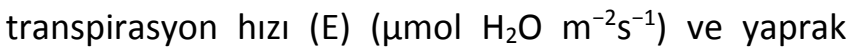

buhar basınç açıklığı $\left(\mathrm{V}_{\mathrm{pdl}}\right)(\mathrm{kPa})$ değerleri ölçülmüştür. Yaprak su potansiyeli (YSP) ölçümleri için arazide belirlenen ağaçlardan alınan yapraklardan delgeçle küvetlere sığacak eşit çapta $(6 \mathrm{~mm})$ diskler alınarak, disk yuvasına yerleştirilmiştir. Yaprak üzerinde homojen 5 doku örneği alınmıştır. Alınan örnekler disk yuvalarına yerleştirildikten sonra 1'er saat beklenerek sonuçlar elde edilmiştir. Elde edilen veriler, SPSS 15.0 istatistik paket programında \%95 güven düzeyinde $(\alpha=0.05)$, T-Testine (bağımsız iki grubun ortalamalarının karşılaştırılması) tabi tutulmuştur.

Tablo 2. Deneme alanlarına ilişkin meteorolojik veriler

\begin{tabular}{lcc}
\hline & $\begin{array}{c}\text { 1. Çalışma } \\
\text { Sahası }\end{array}$ & $\begin{array}{c}\text { 2. Çalışma } \\
\text { Sahası }\end{array}$ \\
\hline $\begin{array}{l}\text { Yıllık Yağış Miktarları } \\
(\mathrm{mm})\end{array}$ & 1153.26 & 979.38 \\
Yıllık Ortalama & & \\
Maksimum Sıcaklık $\left({ }^{\circ} \mathrm{C}\right)$ & 27.7 & 29.3 \\
Im (yağış etkenliği indisi) & 41.63 & 33.40 \\
Yağış Etkenliği Sınıfı & Nemli & Nemli \\
\hline
\end{tabular}

(Artvin meteoroloji istasyonunun $(625 \mathrm{~m})$ iklim verilerinden faydalanarak enterpole edilen ortalama sıcaklık ve yağış değerleri (Çepel, 1995)).

\section{BULGULAR ve TARTIŞMA}

Ekolojik olarak sıcaklık, yağış gibi etkenlerin değişmesiyle doğal ortamında doğu kayınının fizyolojik değişimlerinden net transpirasyon hızı (E) $1484 \mathrm{~m}$ rakımda, ortalama $0.003013\left(\mu \mathrm{mol} \mathrm{H}_{2} \mathrm{O} \mathrm{m}^{-2} \mathrm{~s}^{-1}\right) ; 1162$ $\mathrm{m}$ rakımda ise 0.001319 ( $\mu \mathrm{mol} \mathrm{H}_{2} \mathrm{O} \quad \mathrm{m}^{-2} \mathrm{~s}^{-1}$ ) bulunmuştur (Şekil 1). Yaprak buhar basınç açıklığı $\left(\mathrm{V}_{\text {pdl }}\right)$ üst rakımda 1.3457 (kPa); alt rakımda 1.1105 ( $\mathrm{KPa}$ ) bulunmuştur (Şekil 2). Konu ile ilgili yapılan bazı çalışmalarda, $V_{\text {pdl }}$ ve $E$ gibi fizyolojik aktivitelerin eş zamanlı ve doğru orantılı sonuç verdiği görülmüştür (Sinclair ve Bennett 1998; Fletcher ve ark 2007). Yapılan bu çalışmada ölçülen fizyolojik parametrelerin iki yükselti arasında istatistiksel anlamda değişiklik gösterdiği gözlemlenmiştir.

Su potansiyeli cihazı (PSY PRO, Wescor, USA) ile gerçekleştirilen ölçümler sonucunda, yükseltiye bağlı olarak su potansiyelinin istatistik anlamda değiştiği belirlenmiştir. Birinci deneme alanında (1484 m) yaprak su potansiyeli ortalama -0.912 MPa olarak elde 
edilirken daha düşük yükseltide (1162 $\mathrm{m}$ ) ise yaprak su potansiyeli ortalaması daha yüksek $(-0.582 \mathrm{MPa})$ olarak ölçülmüştür (Tablo 3). Su potansiyelleri arasında fark olmasına karşın Özer ve ark. (1997) çalışmalarında belirttikleri gibi hücrelerin fonksiyonlarını devam ettirmeleri için yeterli olan su içeriğinin korunması, gaz değişimleri arasında farklılığa yol açmamıştır.

Yükseltiye bağlı olarak net transpirasyon hızı ve yaprak buhar basınç açıklığında artma tespit edilmiştir. Kacar ve ark. (2009) transpirasyon hızı ve miktarının bitkiden bitkiye olduğu kadar değişik koşullar altında yetiştirilen aynı bitkiler arasında bile önemli farklılıklar gösterebileceğini ifade etmektedir. $V_{\text {pdl }}$ değerlerindeki azalış bütün türlerde olmamasına karşın çoğu türde stomaların kapanmasıyla sonuçlanmaktadır. Bu yüzden stomatal iletkenlikleri doğrudan etkilediği tam olarak söylenemez (Turner ve ark. 1984) ancak sıcaklık, nem ve rüzgar şiddeti gibi birçok çevresel parametrenin bitkilerde su kaybını etkilemesi, stomatal hareketlerin de etkilendiğini göstermektedir (Jarvis ve Morison 1981; Ball ve ark. 1987; Aphalo ve Jarvis 1993; Comstock ve Mencuccini 1998). YSP değerlerinin yükseltinin artmasıyla birlikte azalması ve E değerlerinin ise artması birçok çalışmada da ortaya konmuştur (Camacho ve ark. 1974; Kırnak ve Demirtaş 2002).

$V_{p d l}$ değerleri yapılan çalışmada $E$ değerleriyle doğru orantılı hareket etmektedir. Yükselti boyunca ilerledikçe atmosferik basıncın düşmesi evoporasyon ve bitki transpirasyonunda artışı meydana getirmektedir (Gale 1972b). Transpirasyon, fotosentetik aktif radyasyon ve buhar basınç açıklığı gibi günlük devir sergiler (Schulze ve ark. 1985; Monteith 1995; Adelman ve ark. 2008). Yaprağın düşük basınçtaki $\mathrm{CO}_{2}$ difüzyonunun aksine, daha düşük atmosfer basıncında havadaki su buharı için yükseltiden dolayı difüzyon katsayısına tekabül eden artışa bağlı olarak yapraktan havaya su difüzyonunun artması beklenir (Smith ve Geller 1979). Yapılan çalışmada bulunan sonuçlara benzer olarak Fredeen ve Sage (1999) laboratuvardaki deneyleri sonucunda E ve VPD değerlerindeki artışın yaprağın sıcaklığıyla birlikte doğrusal olarak değiştiğini desteklemiştir. Çalıkoğlu ve Tilki (2004)'nin Lübnan ve Macar Meşesinde kurak dönemdeki transpirasyon analizi çalışmalarında, bitkideki su potansiyelinin artmasıly turgor basıncındaki artmaya dikkat çekilmiştir. Transpirasyon değerlerinin artması YSP değerlerini düşürmüştür. Dirik (1994) üç farklı çam türünün kurak periyottaki transpirasyon tutumlarını ele aldığı çalışmada; tam doygun haldeki sürgünlerin daha hızlı transpirasyon yaptığını ve su kayıplarına karşı korunmak amacıyla stomaların kapanmasıyla transpirasyonun su potansiyelinin azalmasıyla arttığını belirlemiştir. Bu durum da direkt olarak $E$ ve $V_{p d l}$ değerlerindeki artışın YSP değerlerini düşürdüğünü göstermektedir.

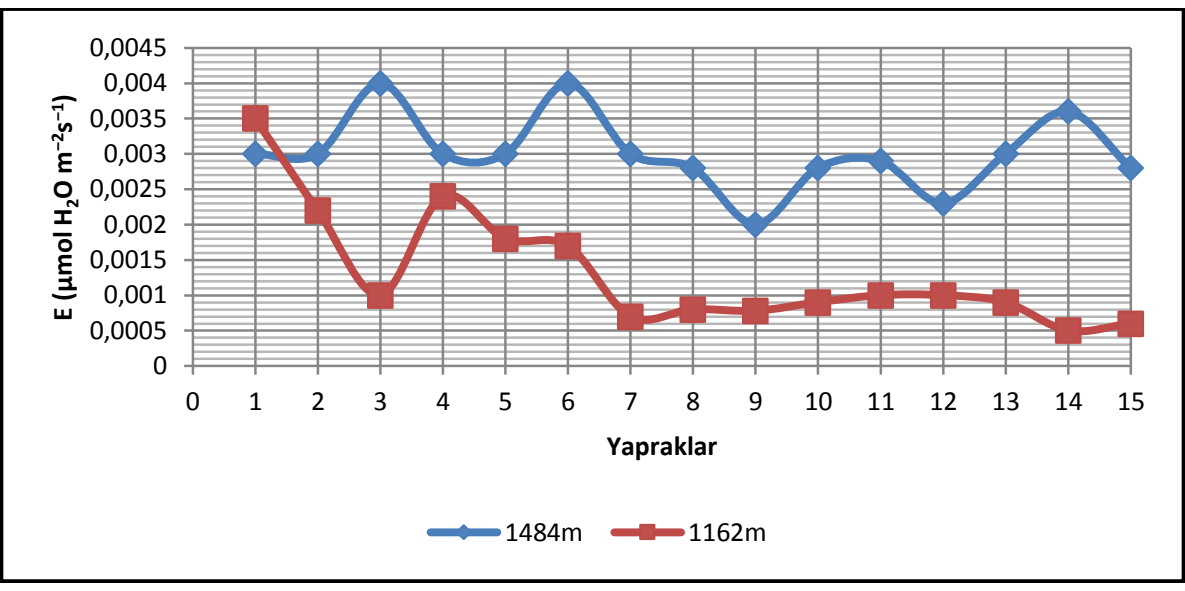

Şekil 1. Yükselti gradiyentine bağlı yapraklardaki transpirasyon oranları 


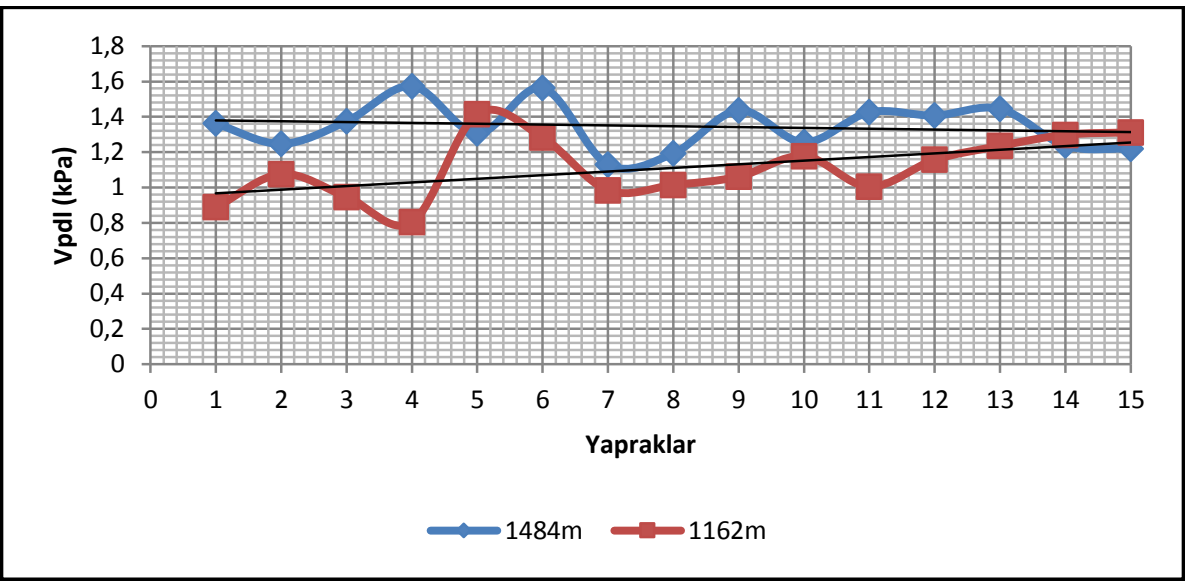

Şekil 2. Yükselti gradiyentine bağlı yapraklardaki buhar basınç açıklığı

Tablo 3. Deneme alanlarındaki ağaçların yaprak su potansiyeli (YSP) değerleri

\begin{tabular}{lccccc}
\hline Deneme Alanları ve Ağaçlar & 1.YSP (MPa) & 2.YSP (MPa) & 3.YSP (MPa) & 4.YSP (MPa) & $\begin{array}{c}\text { Ortalama YSP } \\
\text { (MPa) }\end{array}$ \\
\hline 1. D.A. 1. Ağaç & -0.74 & -0.77 & -0.97 & -0.85 & -0.832 \\
1. D.A. 2. Ağaç & -0.94 & -0.86 & -0.9 & -0.9 & -0.9 \\
1. D.A. 3. Ağaç & -0.55 & -0.49 & -1.04 & -0.73 & -0.702 \\
1. D.A. 4. Ağaç & -0.71 & -2.45 & -0.91 & -1.3566 & -1.36 \\
1. D.A. 5. Ağaç & -0.78 & -0.73 & -0.8 & -0.77 & -0.77 \\
\hline 1. D.A Ortalama Değerler & & & -0.912 & & \\
& & & & & \\
\hline 2. D.A. 1. Ağaç & -0.39 & -0.31 & 0.02 & -0.2266 & -0.227 \\
2. D.A. 2. Ağaç & -0.54 & -0.69 & -0.94 & -0.7233 & -0.723 \\
2. D.A. 3. Ağaç & -0.82 & -0.64 & -0.75 & -0.7366 & -0.737 \\
2. D.A. 4. Ağaç & -0.03 & -0.94 & -0.92 & -0.61 & -0.61 \\
2. D.A. 5. Ağaç & -0.54 & -0.6 & -0.7 & -0.6133 & -0.613 \\
\hline 2. D.A Ortalama Değerler & \multicolumn{5}{c}{-0.582} \\
\hline
\end{tabular}

\section{SONUÇLAR}

Yapılan çalışma sonucunda, üst rakımda yaprak su potansiyeli azalırken, transpirasyon ve buhar basınç açığının alt rakıma göre daha fazla olduğu görülmüştür. Çalışılan lokasyonda üst rakımdaki Doğu kayını bireylerinde daha az su potansiyeli olmasına rağmen fizyolojik aktivitelerinin hayati ihtiyaçlarını karşılayabildiği yani hücresel su kaybının yaşanmadığı görülmüştür. Yükseltiye göre yaprak su potansiyelleri arasında fark bulunmuştur. Bu farkın su potansiyeli ölçümleri yapılan ağaçların bulundukları yere düşen yağış miktarıyla veya toprak altı suyundan yararlanma durumuna göre değişebildiği düşünülebilir. Farklılık gösteren yaprak su potansiyellerinin fotosentezi ve stomatal iletkenlikleri etkilememesi, fizyolojik olayların gerçekleştiği hücrelerde su içeriğinin yeterli olmasıyla açıklanabilir. Deneme alanlarındaki ağaçların yöredeki dağılımları fizyolojik açıdan bulundukları yükseltiyle uyum içinde metabolik faaliyet gösterdiği belirlenmiştir. Deneme alanlarının olduğu lokasyonda, üst rakımda bulunan ağaçların, ölçülen fizyolojik aktiviteler bakımından alt rakımda bulunan ağaçlara nazaran daha yüksek potansiyele sahip olduğu belirlenmiştir. Yapılan çalışma sonucunda ortaya çıkan, aynı yöre ve aynı bakıda yükseltiye bağlı olarak ölçülen fizyolojik özelliklerdeki (yaprak su potansiyeli, transpirasyon, yaprak buhar basınç açıklığı) farklııı, ağaçlandırma çalışmalarında tohum toplanan yerin önemli olabileceğini de göstermektedir.

$\mathrm{Bu}$ çalışmada yükselti değişimlerine bağlı olarak ölçülen birçok parametre farklı türlerde farklı sonuçlar ortaya koyma potansiyeline sahiptir. Dolayısıyla tür 
çeşitliliğinin ve yükselti basamaklarının artırıldığı benzer çalışmalarla, konuyla ilgili daha kapsamlı sonuçlar elde edilebilecektir.

Teşekkür: Bu çalışma Artvin Çoruh Üniversitesi Bilimsel Araştırma Projeleri Koordinatörlüğünce desteklenmiştir (Proje no: 2013.F10.01.05).

\section{KAYNAKLAR}

Addington RN, Mitchell RJ, Oren R, Donovan LA (2004) Stomatal sensitivity to vapor pressure deficit and its relationship to hydraulic conductance in Pinus palustris. Tree Physiology 24:561-569

Adelman JD, Ewers BE, Mackay DS (2008) Use of temporal patterns in vapor pressure deficit to explain spatial autocorrelation Dynamics in tree transpiration. Tree Physiology 28:647-658

Anderson DB (1936) Relative Humidity or Vapor Pressure Deficit. Ecology 17:277-282

Aphalo PJ, Jarvis PG (1993) The boundary layer and the apparent responses of stomatal conductance to wind speed and to the mole fractions of $\mathrm{CO} 2$ and water vapour in the air. Plant Cell and Environment 16:771-783

Ball JT, Woodrow IE, Berry JA (1987) A model predicting stomatal conductance and its contribution to the control of photosynthesis under different environmental conditions. Progress in Photosynthesis Research 4:221-228

Bresson CC, Kowalski AS, Kremet A, Delzon S (2009) Evidence of altitudinal Increase in photosynthetic capacity: gas exchange measurements at ambient and constant $\mathrm{CO}_{2}$ partial pressures. Annals of Science 66(5):505

Camacho SE, Kaufman MR, Hall AE (1974) Leaf water potential response to transpiration by Citrus. Physiol Plant 31:101-105

Chabot BF, Hicks DJ (1982) The ecology of leaf life spans. Annual Review of Ecology and Systematics 13:229-259

Comstock J, Mencucccini M (1998) Control of stomatal conductance by leaf water potential in Hymenoclea salsola (T.\&G.), a desert subshrub. Plant Cell and Environment 21:1029-1038

Cunningham SC (2004) Photosynthetic responses to vapour pressure deficit in temperate and tropical evergreen rainforest trees of Australia. Oecologia 142:521-528

Çalıkoğlu M, Tilki F (2004) Lübnan meşesi (Quercus libani Olivier) ve Macar meşesi ( $Q$. frainetto Ten.) fidanlarında kurak dönemdeki transpirasyon analizi. İstanbul Üniversitesi Orman Fakültesi Dergisi 54:133-142

Çepel N (1995) Orman Ekolojisi 4. Baskı. İstanbul Üniversitesi Orman Fakültesi Yayını, No: 433, İstanbul

Dirik H (1994) Üç yerli çam türünün (Pinus brutia Ten., Pinus nigra Arn. Ssp. pallasiana Lamb. Holmboe, Pinus pinea L.) kurak peryottaki transpirasyon tutumlarının ekofizyolojik analizi. İstanbul Üniversitesi Orman Fakültesi Dergisi 44:111-121

Fletcher AL, Sinclair TR, Allen LH (2007) Transpiration responses to vapor pressure deficit in well watered "slow-wilting" and commercial soybean. Environmental and Experimental Botany 61:145-151

Fredeen AL, Sage RF (1999) Temperature and humudity effects on branchelet gas-exchange in white spruce: an explanation fort he increase in transpiration with branchlet temperature. Trees 14:161-168

Friend AD, Woodward FI (1990) Evolutionary and ecophysiological responses of mountain plants to the growing season environment. Advances in Ecological Research 20: 59-124

Gale J (1972a) The availability of carbon dioxide for photosynthesis at high altitudes: theoretical considerations. Ecology 53: 494497

Gale J (1972b) Elevation and transpiration. Some theoretical considerations, with special reference to Mediterranean type climates. Journal of Applied Ecology 9: 691-702

Hetherington AM, WoodwardFI (2003) The role of stomata in sensing and driving environmental change. Nature 424:901908

Hiesey WM, Nobs MA, Björkman O (1971) Experimental studies on the nature of species. V Biosystematics, genetics, and physiological ecology of the Eryanthe section of Mimulus. Cranegie Institue Washington Publishes

Jarvis PG, Morison JIL (1981) The control of transpiration and photosynthesis by the stomata. In Stomatal Physiology (Ed. Jarvis PG and Mansfield TA). Cambridge University Press, New York, pp 247-279

Kacar, B., Katkat AV, Öztürk Ş (2009) Bitki Fizyolojisi. Nobel Yayın, Ankara

Kadıoğlu A (2011) Bitki Fizyolojisi. Karadeniz Teknik Üniversitesi, Fen Fakültesi, Biyoloji Bölümü. 5. Baskı. Trabzon

Kırnak H, Demirtaş MN (2002) Su stresi altındaki kiraz fidanlarında fizyolojik ve morfolojik değişmelerin belirlenmesi. Atatürk Üniversitesi Ziraat Fakültesi Dergisi 33:256-270

Kikuzawa K (1989) Ecology and evolution of phenological pattern, leaf longevity and leaf habit. Evolutionary. Trends Plants 3:105110

Körner C, Diemer M (1987) In situ photosyntetic responses to light, temperature and carbon dioxide in herbaceous plants from low, mid and high altitude. Functional Ecology 1:179-194

Körner C (2007) The Use of "Altitude" in Ecological Research. Institute of Botany, University of Basel. Ecol Evol 22:569-575

Kramer PJ, Kozlowski TT (1960) Physiology of Trees. McGraw-Hill Book Company, Inc. London

Kumar N, Kumar S, Surender KV, Paramvir SA (2005) Effect of altitude on the primary products of photosynthesis and the associated enzymes in barley and wheat. Photosynthesis Research 88:63-71 
Li J, Li X (2014) Response of stomatal conductance of two tree species to vapor pressure deficit in three climate zones. Journal of Arid Land 6:771-781

Ludlow MM (1980) Adaptive significance of stoma responses to water stres. Adaptation of plants to water and hing temperature stress. Wiley, New York, pp 122-138

Monteith JL (1995) A reinterpretation of stomatal response to humidity. Plant Cell and Environment 18:357-364

Morales VL, Ortega OL, Fernandez JR Munoz LB (2008) JAPIEST: An integral intelligent system for the diagnosis and control of tomatoes diseases and pests in hydroponic greenhouses. Expert System with Applications 35: 1506-1512

Özer H, Karadoğan T, Oral E (1997) Bitkilerde Su Stresi ve Dayanıklııı Mekanizması. Atatürk Ünversitesi Ziraat Fak. Dergisi 28:488-495

Prenger JJ, Ling PP (2001) Greenhouse condensation control: Understanding and using vapor pressure deficit (VPD) Fact Sheet (Series) AEX-800. Ohio State University

Schulze ED, Cernak J, Matyssek R, Penka M, Zimmerman R, Vasicek F, Gries W, Kucera J (1985) Canopy transpiration and water fluxes in the xylem of the trunk of Larix and Picea trees- a comparison of xylem flow, porometer and cuvette measurements. Oecologia 66:475-483

Smith WK, Geller GN (1979) Plant transpiration at high elevations: Theory, field measurements, and comparisons with desert plants. Oecologia 41:109-122

Sinclair TR, Bennett JM (1998) Principles of Ecology in Plant Production (Modular Texts Series). CAB International, Florida USA

Taiz L, Zeiger E (2008) Plant Physiology. 3rd ed. Sinauer Assoc. Inc. MA

Tranquillini W (1964) The physiology of plants at high altitudes. Annual Review of Plant Physiology and Plant Molecular Biology $15: 245-362$

Turner NC, Schulze ED, Gollan T (1984) The responses of stomata and leaf gas exchange to vapour pressure deficits and soil water content I. Species comparisons at high soil water contents. Oecologia 63:338-342 